\title{
Effectiveness of orthodontic temporary anchorage devices in canine retraction and anchorage preservation during the two- step technique: a systematic review and meta-analysis
}

Haonan Tian ${ }^{1,2}$, Congman Xie ${ }^{1,2}$, Min Lin ${ }^{1,2}$, Hongmei Yang ${ }^{1,2}$ and Aishu Ren ${ }^{1,2,3^{*}}$ (D)

\begin{abstract}
Background: Temporary anchorage devices have been used for decades in orthodontic practice for many applications. The aim of this systematic review was to assess the effectiveness of orthodontic temporary anchorage devices in canine retraction during the two-step technique.

Methods: A search was systematically performed for articles published prior to June 30, 2019 in five electronic databases (PubMed, Embase, Cochrane Central Register of Controlled Trials, Web of Science, Scopus). The risk of bias was assessed using the Cochrane risk of bias tool for randomized controlled trials (RCTs) and the risk of bias in nonrandomized studies of interventions (ROBINS-I) tool for controlled clinical trials (CCTs). The Grading of Recommendation, Assessment, Development and Evaluation (GRADE) approach was used for the quality assessment. Data concerning the mean difference in mesial molar movement and extent of canine retraction were extracted for statistical analysis. The mean differences and 95\% confidence intervals were analyzed for continuous data. A meta-analysis with a random-effects model for comparable outcomes was carried out.

Results: Three RCTs and five CCTs were finally included. Meta-analysis showed a significant increase not only in anchorage preservation in the implant anchorage group in both the maxilla $(1.56 \mathrm{~mm}, 95 \% \mathrm{Cl}: 1.14$ to $1.98, P<$ $0.00001)$ and the mandible $(1.62 \mathrm{~mm}, 95 \% \mathrm{Cl}: 1.24$ to $2.01, P<0.00001)$ but also in canine retraction in the implant anchorage group in both the maxilla $(0.43 \mathrm{~mm}, 95 \% \mathrm{Cl}: 0.16$ to $0.69, P=0.001)$ and the mandible $(0.26 \mathrm{~mm}, 95 \% \mathrm{Cl}$ : 0.02 to $0.49, P=0.03)$.
\end{abstract}

Conclusions: There is very low-quality evidence showing that implant anchorage is more efficient than conventional anchorage during canine retraction. Additional high-quality studies are needed.

Keywords: Orthodontic implants, Canine retraction, Systematic review, Meta-analysis

\footnotetext{
* Correspondence: 500220@hospital.cqmu.edu.cn

${ }^{1}$ College of Stomatology, Chongqing Medical University, No.426 Songshibeilu Road, Yubei District, Chongqing, China

${ }^{2}$ Chongqing Key Laboratory of Oral Diseases and Biomedical Sciences, Chongqing, China

Full list of author information is available at the end of the article
}

(c) The Author(s). 2020 Open Access This article is licensed under a Creative Commons Attribution 4.0 International License, which permits use, sharing, adaptation, distribution and reproduction in any medium or format, as long as you give appropriate credit to the original author(s) and the source, provide a link to the Creative Commons licence, and indicate if changes were made. The images or other third party material in this article are included in the article's Creative Commons licence, unless indicated otherwise in a credit line to the material. If material is not included in the article's Creative Commons licence and your intended use is not permitted by statutory regulation or exceeds the permitted use, you will need to obtain permission directly from the copyright holder. To view a copy of this licence, visit http://creativecommons.org/licenses/by/4.0/. The Creative Commons Public Domain Dedication waiver (http://creativecommons.org/publicdomain/zero/1.0/) applies to the data made available in this article, unless otherwise stated in a credit line to the data. 


\section{Background}

Extracting the premolars and closing the extraction space completely are necessary for orthodontic treatment, especially for patients with bimaxillary protrusion $[1,2]$. Additionally, maximum posterior anchorage preservation is crucial for space closure [3-5]. Although transpalatal arches (TPAs) [6], Nance arches [7] and headgear [8] have been widely used for anchorage reinforcement, anchorage loss, mesial inclination of the dental anchorage and molar extrusion, which are undesirable, are still common in orthodontic practice [911]. Temporary anchorage devices (TADs) have been used since the last century and have become an alternative reinforcement method to provide anchorage during space closure [12, 13]. Many studies have investigated the efficiency of TADs and have shown that space closure [13-15], tooth intrusion [16] and maxillary expansion [17] can be aided with TADs.

Two-step retraction and en masse retraction are two methods for achieving extraction space closure [18, 19]. Both techniques are efficient for space closure, and there is no significant difference between the two methods in the extent of anterior tooth retraction or molar anchorage loss $[5,18,20]$. However, it takes more time to achieve space closure with two-step retraction than with en masse retraction $[5,21]$.

A published systematic review [22] compared the difference between en masse and two-step retraction regarding the treatment outcomes and concluded that both methods may lead to similar skeletal improvement, but TADs with en masse retraction can lead to better anchorage control, more anterior retraction and a better facial profile. Many studies [23-25] have shown that en masse retraction with TADs is clinically superior in terms of anchorage preservation, but in orthodontic practice, severe anterior crowding or midline discrepancies may prevent the doctor from performing this procedure [21, 26]. Furthermore, anchorage loss may occur during the initial stage of leveling and aligning [27-29], so early application of TADs may be necessary to retract the canine backward to align the front teeth and attain better anchorage control, especially for cases of severe anterior crowding. Currently, there exists little research on two-step retraction with TADs, and whether it can lead to the same outcome or an even better outcome than en masse retraction with TADs remains inconclusive. Canine retraction is the first step of the two-step retraction method [20], the completion of which is crucial for subsequent incisor retraction.

Skeletal anchorage has two forms, direct skeletal anchorage and indirect skeletal anchorage [30, 31]; a previous study [15] indicated that indirect TADs was not significantly different from conventional anchorage in terms of anchorage preservation during canine retraction, whereas other studies have found a positive effect $[14,32,33]$ with direct TADs. Therefore, it is unclear whether the mode of TADs has different effects on the issue. Therefore, this systematic review and metaanalysis aimed to compare the potential of TADs and conventional anchorage in terms of anchorage preservation and canine retraction during the initial canine retraction step of the two-step technique.

\section{Methods}

This systematic review was carried out according to the Preferred Reporting Items for Systematic Reviews and Meta-Analyses (PRISMA) statement [34]. The eligibility criteria were based on PICOS, as follows:

Study design: Prospective randomized and controlled clinical trial. The exclusion criteria were as follows: review articles, animal studies, case reports, lack of a control group, partial canine retraction and en masse retraction of the anterior teeth, and space closure not performed with sliding mechanics.

Population: Orthodontic patients requiring extraction of the bilateral first premolars and retraction of the canines during the two-step technique.

Intervention: Miniscrew implants for anchorage preservation during the first phase of the two-step retraction technique.

Comparison: Conventional anchorage methods for anchorage preservation during the first phase of the two-step retraction technique.

Outcomes: The primary outcomes were mesial movement of the first molars (anchorage loss) and the extent of canine retraction in both the maxilla and mandible. The secondary outcomes were tipping of the canines and molars and vertical molar movement. All the outcomes were measured in two cephalometric radiographs; one was taken before canine retraction, and the other one was taken after the completion of canine retraction.

\section{Protocol registration}

The protocol for this systematic review was registered on PROSPERO (CRD42019123343).

\section{Search strategy and study selection}

The following electronic databases were searched for published articles with no language restriction prior to June 30, 2019: PubMed, Embase, Cochrane Central Register of Controlled Trials, Scopus, and Web of Science. The following journals were manually screened: European Journal of Orthodontics, Journal of Orthodontics, American Journal of Orthodontics \& Dentofacial Orthopedics, and Angle Orthodontist. Four reviewers (THN, XCM, YHM, LM) independently selected the 
studies, and disagreements were resolved by consensus. The search strategy is summarized in Additional file 1.

\section{Data extraction}

The following data were extracted: study identification, publication data, sample size, age of patients, types of conventional anchorage, implant diameter, length, and location, extent of horizontal and vertical molar movement, change in molar and canine inclination, extent of canine retraction, and treatment duration. Data extraction was independently conducted by four reviewers (THN, XCM, YHM, LM). Differences were resolved by reviewing the included studies until a consensus was reached. If additional information was needed, the authors contacted an author of the study.

Risk of bias in individual studies and quality of evidence Four reviewers (THN, XCM, YHM, LM) independently assessed the quality of the included studies. Cochrane Collaboration's risk of bias tool [35] for randomized clinical trials (RCTs) was used to assess the quality of the RCTs. The studies were evaluated as having a low, moderate, or high risk of bias. If one of the domains (random sequence generation, allocation concealment, blinding of the participants and personnel, blinding of the outcome assessment, incomplete outcome data, selective reporting, and other bias) was assessed to be at a high risk of bias, the study was given an overall score of a high risk. The risk of bias in nonrandomized studies of interventions (ROBINS-I) [36] tool was used for controlled clinical trials (CCTs). The Grading of Recommendation, Assessment, Development and Evaluation (GRADE) approach was used to evaluate the quality of evidence in four domains: strong, moderate, low, and very low. Any disagreements between the reviewers were resolved by consensus.

\section{Dealing with zero values}

In the event a zero value was presented in the included articles (mean $+\mathrm{SD}$ ), the SD value was changed to 0.01 $\mathrm{mm}$ to enable statistical analysis.

\section{Data synthesis}

Meta-analysis was performed only if the studies reported the same outcome measures. Specifically, a metaanalysis of the mean difference in first molar mesial movement (anchorage loss) and canine retraction was carried out. All clinical studies were statistically evaluated, and significance was established at $P<0.05$. Heterogeneity was tested using the $\mathrm{Q}$ and $\mathrm{I}^{2}$ statistics, and a score of greater than $50 \%$ indicated extreme heterogeneity. The results of the analyses are shown as forest plots. If significant heterogeneity existed in the study, then subgroup or sensitivity analysis was performed, including analysis of the study design, type of conventional anchorage, and type of implant anchorage. A funnel plot was used to assess publication bias (including more than 10 studies). All statistical analyses were completed with The Cochrane Review Manager (RevMan version 5.1).

\section{Results \\ Study selection}

The study selection process is illustrated in Fig. 1. A total of 583 articles were identified, and upon review of the titles and abstracts, 420 were excluded, leaving 19 articles. After reading the full texts, 8 studies were included in the present review for qualitative and quantitative synthesis. The 8 remaining studies included three RCTs [14, 32, 33] and five CCTs [15, 37-40]. Information about the excluded records is summarized in Additional file 2.

\section{Study characteristics}

The characteristics of the included studies are presented in Table 1, and the relevant data extracted from the included articles are shown in Table 2. Three RCTs [14, $32,33]$ and five CCTs $[15,37-40]$ were included in the present review. Six studies investigated direct implant anchorage for canine retraction, while two studies used indirect implant anchorage. Four studies [14, 38-40] compared TADs with dental anchorage in a split-mouth study. Two studies $[32,33]$ compared TPAs with TADs in the maxilla in a parallel study; one [33] also compared lingual bars with TADs in the mandible. The other one [15] compared midpalatal implant-reinforced TPAs with conventional TPAs in the maxilla. One study [37] compared midpalatal implants with dental anchorage in the maxilla and TADs with dental anchorage in the mandible. Three studies $[14,38,39]$ inserted implants in both the maxilla and the mandible when the patients' ANB angle was between $2^{\circ}$ and $4^{\circ}$ but in only the maxilla when the ANB angle was greater than $5^{\circ}$ as a part of camouflage treatment.

\section{Risk of bias assessment}

Three RCTs [14, 32, 33] were considered to have a high risk of bias because none of them reported using an appropriate strategy for blinding the participants or personnel. The study by Davis et al., 2018 [14], used a computer-generated program to randomly allocate the sides only, and did not perform allocation concealment. The randomization method used in the study by Sharma et al., 2012 [32], involved random numbers generated by a computer, but the allocation was performed by alternation, which leads to a high risk of bias for allocation concealment. The third study [33] did not report the use of any randomization method, which resulted in an unclear 


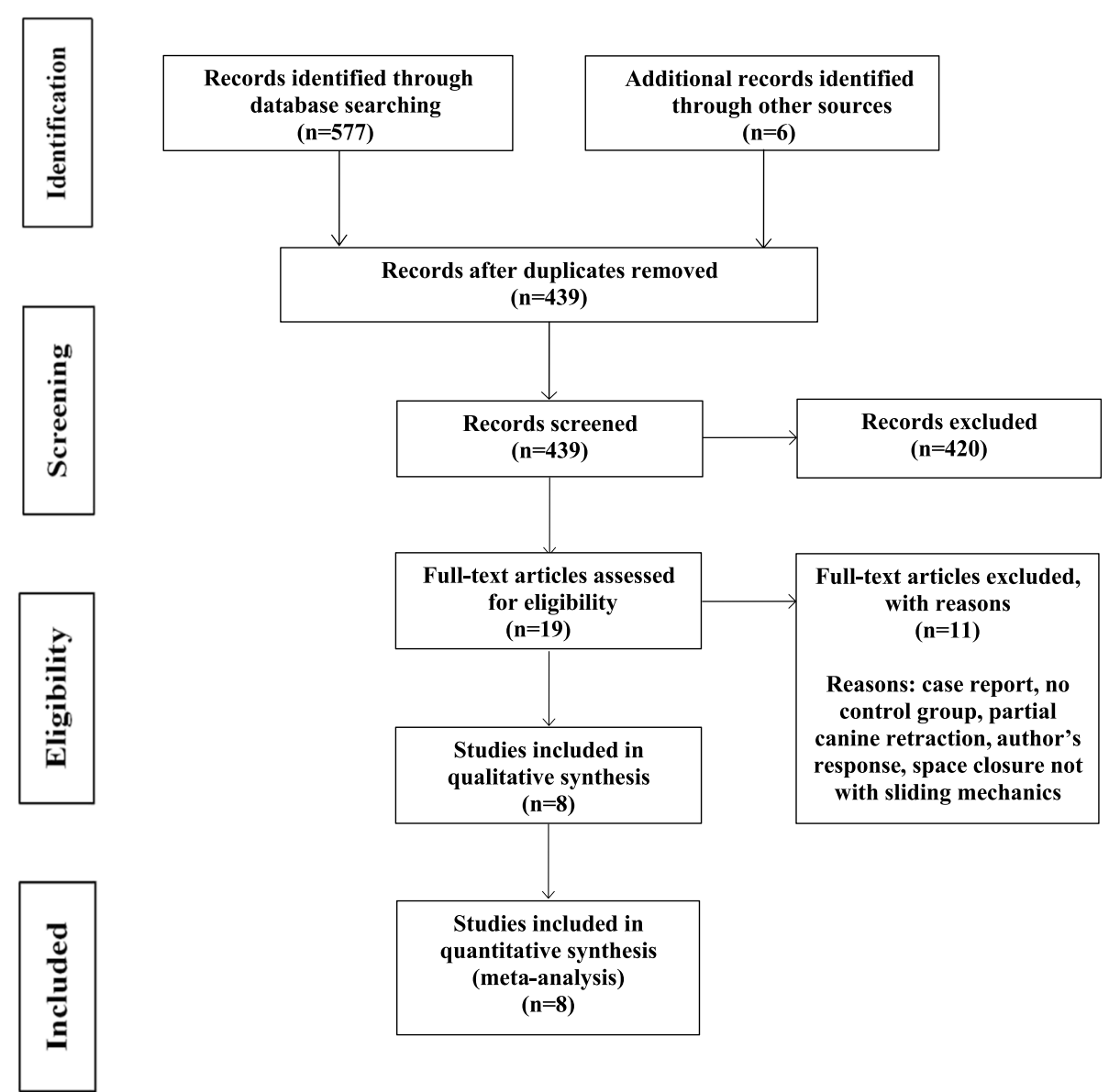

Fig. 1 PRISMA flow diagram for the study selection process

risk of bias. Blinding of the outcome assessment was also difficult in the studies because the TADs could be observed in lateral cephalograms. However, Sharma et al., 2012 [32], removed the miniscrew implants and TPAs before obtaining the cephalometric radiographs that were taken after the completion of canine retraction, resulting in a low risk of bias. Davis et al., 2018 [14], used guide wires to differentiate the right and left sides on the lateral cephalograms, resulting in a high risk of bias. Gökçe et al., 2012 [33], did not report using a process for blinding the assessor, resulting in an unclear risk of bias. The quality assessment results of the RCTs are summarized in Fig. 2.

Five CCTs [15, 37-40] were assessed using the ROBINS-I [36] tool. The study by Hedayati et al., 2007 [37], gave inadequate information regarding the patient inclusion criteria, Thiruvenkatachari et al., 2006 [38], and Thiruvenkatachari et al., 2008 [39], only inserted implants in the maxilla when the ANB angle was greater than $5^{\circ}$ as a part of camouflage treatment, which led to a moderate risk of bias in selection. In the measurement of outcomes, Thiruvenkatachari et al., 2006 [38], and
Thiruvenkatachari et al., 2008 [39], used wires identifiers, and Chaudhary et al., 2014 [40], used CBCTgenerated 2D cephalometric with implants clearly seen on it, which led to a serious risk of bias in the measurement of outcomes. Borsos et al., 2012 [41], used an opaque marker in the approximate position of the implant in both groups, which led to a low risk of bias. Finally, Hedayati et al., 2007 [37], did not present information regarding outcome measurements. Therefore, the overall bias across studies was serious bias in three studies [38-40], moderate bias in one study [37] and low bias in another study [41]. The risk of bias information for the included CCTs is summarized in Table 3.

\section{Primary outcome measures}

\section{Mesial molar movement (anchorage loss)}

Seven studies [14, 15, 32, 33, 37, 38, 40] were qualified for meta-analysis, and the total and subgroup analysis results are given in Fig. 3(a, b). In the maxilla, the results showed a total mean difference of $1.56 \mathrm{~mm}$ (95\% CI: 1.14 to 1.98$)$, with statistical significance $(P<0.00001)$. 


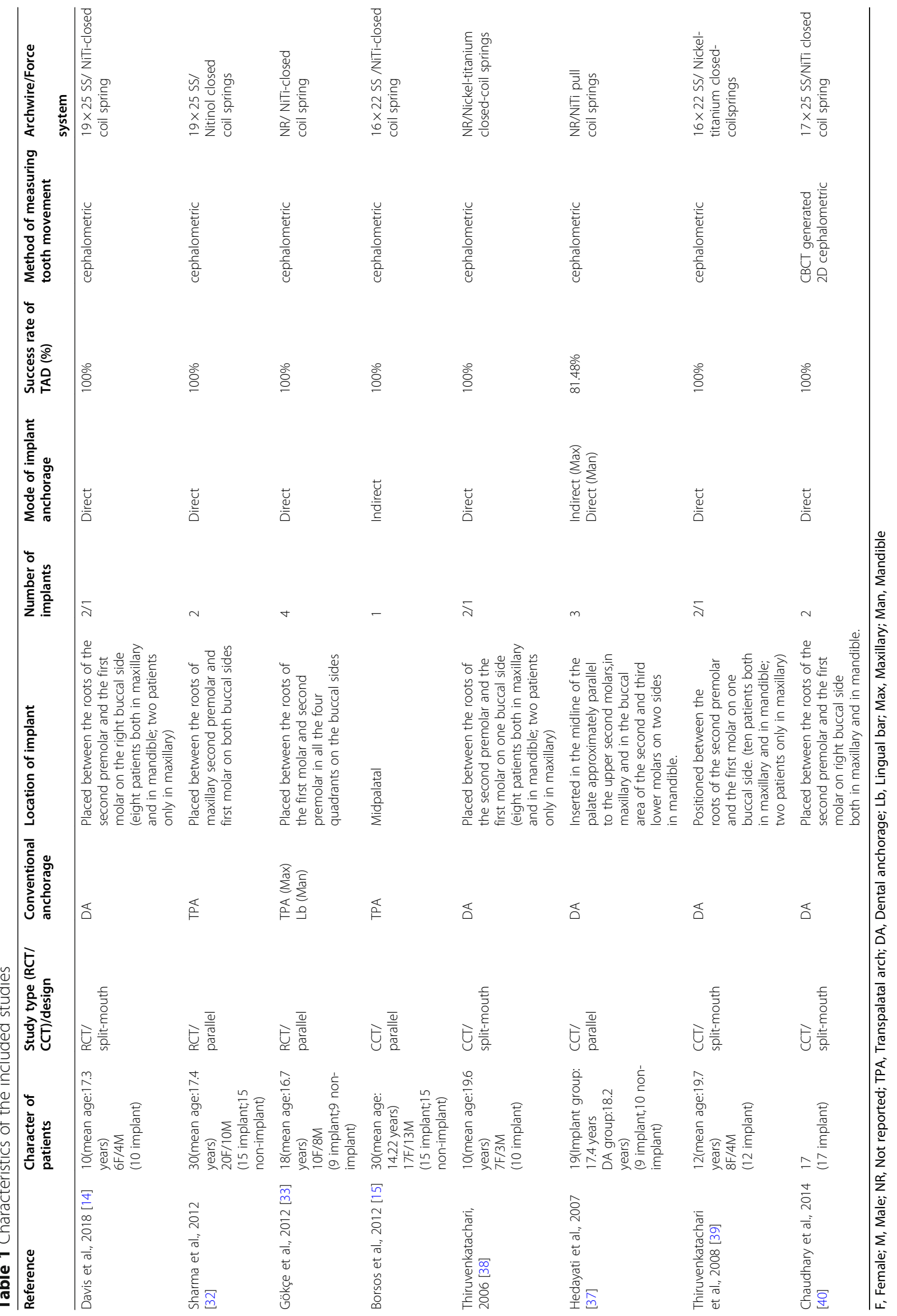




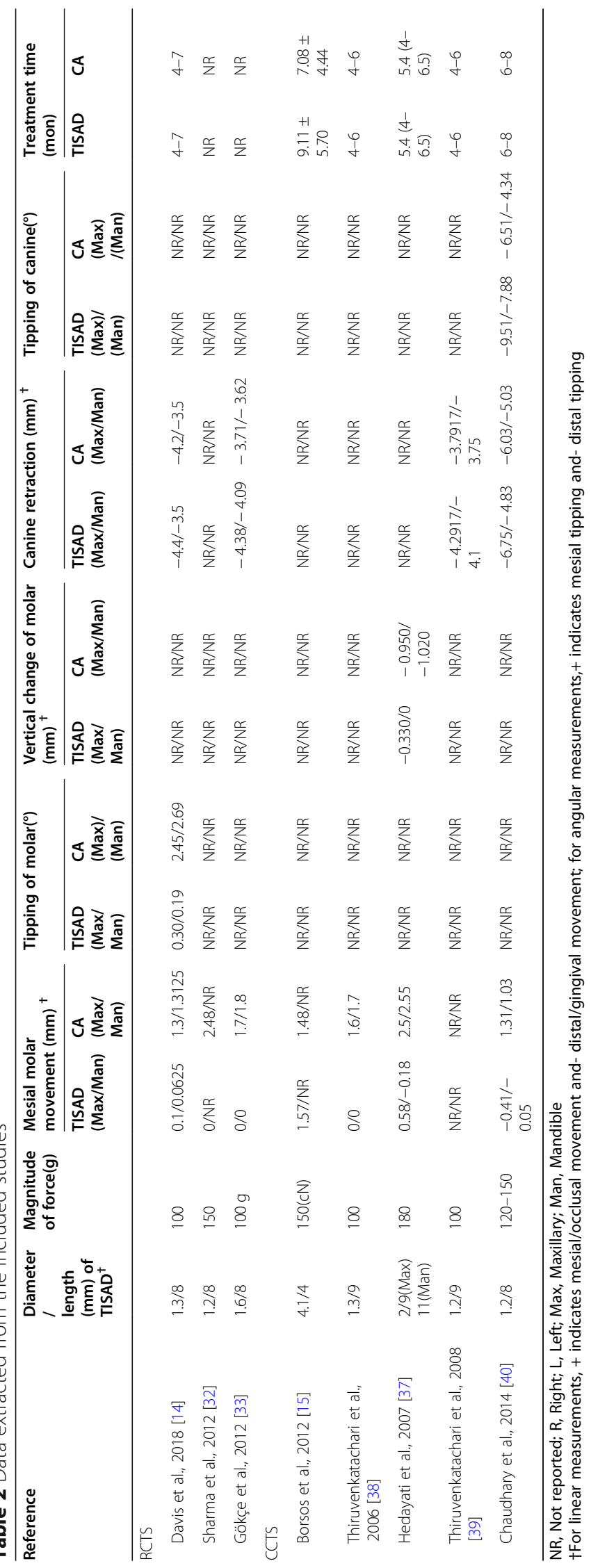




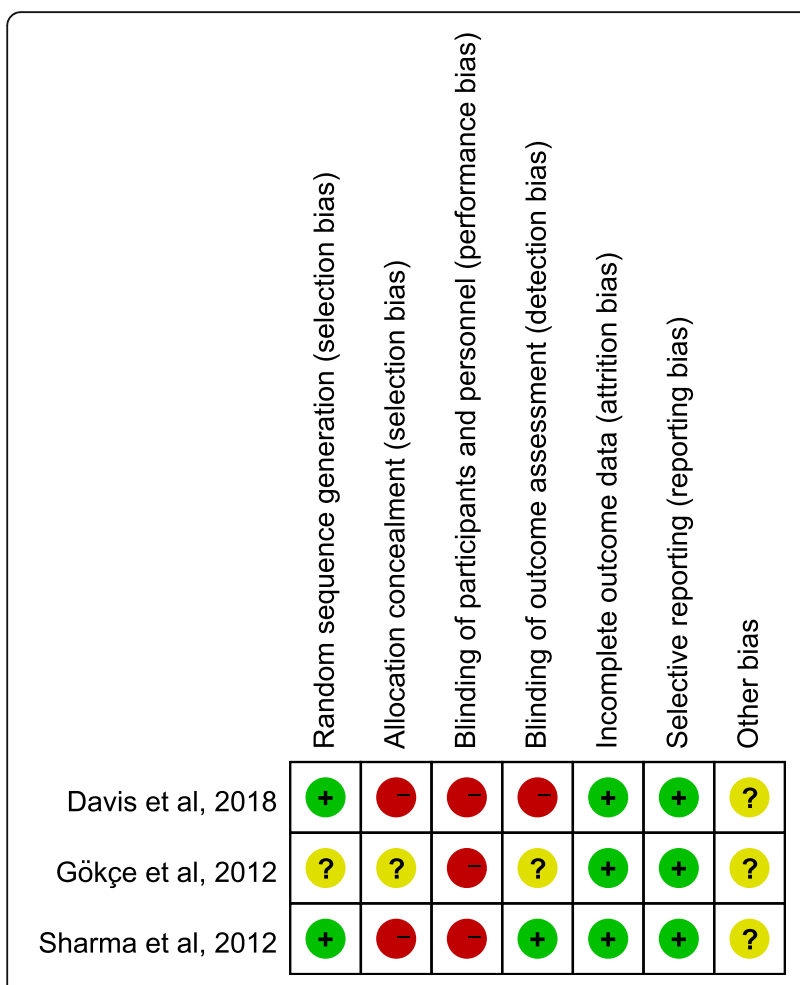

Fig. 2 Risk of bias summary for randomized controlled trials

Subgroup analysis showed a mean difference of $1.74 \mathrm{~mm}$ (95\% CI: 1.32 to $2.17, \mathrm{P}<0.00001$ ) in the direct group and a mean difference of $0.93 \mathrm{~mm}$ ( $95 \% \mathrm{CI}:-1.04$ to 2.90, $P=0.35$ ) in the indirect group. In the mandible, the results showed a total mean difference of $1.62 \mathrm{~mm}(95 \%$ CI: 1.24 to 2.01$)$, with statistical significance $(\mathrm{P}<$ 0.00001). Subgroup analysis showed a mean difference of 1.45 (95\% CI: 1.13 to $1.78, \mathrm{P}<0.00001$ ) in the direct group. Only one study [37] included a mandibular indirect group; the results showed a mean difference of 2.73 $\mathrm{mm}(95 \% \mathrm{CI}: 1.98$ to $3.48, \mathrm{P}<0.00001)$. In both the maxilla and mandible, the direct and indirect groups showed substantial heterogeneity, with $\mathrm{I}^{2}>50 \%$.

\section{Distal canine movement}

Four studies [14, 33, 39, 40] were qualified for metaanalysis of both maxillary and mandibular data, and the results are given in Fig. 3(c, d). In the maxilla, the results showed a total mean difference of $0.43 \mathrm{~mm}$ (95\% CI: 0.16 to 0.69$)$, with statistical significance $(P=0.001)$; $\mathrm{I}^{2}=0$. In the mandible, the results showed a total mean difference of $0.26 \mathrm{~mm}$ (95\% CI: 0.02 to 0.49$)$, with statistical significance $(P=0.03) ; \mathrm{I}^{2}=0$.

\section{Secondary outcome measures}

One study [14] included mesial tipping of the maxillary and mandibular molars with direct TADs. The results showed a mean tipping of $0.30^{\circ}$ degrees in the TAD group and a mean tipping of $2.45^{\circ}$ in the conventional anchorage group in the maxilla $(P=0.000)$; in the mandible, the values were $0.1875^{\circ}$ and $2.6875^{\circ}(\mathrm{P}=0.001)$, respectively.

One study [37] included vertical displacement of the maxillary and mandibular molars with indirect TADs. The results showed a mean intrusion of $0.33 \mathrm{~mm}$ in the study group and $0.95 \mathrm{~mm}$ in the control group in the maxilla; in the mandible, the results showed a mean intrusion of $0 \mathrm{~mm}$ in the study group and $1.02 \mathrm{~mm}$ in the control group. With consideration of the cephalometric error $(-0.55 \mathrm{~mm})$, slight maxillary molar extrusion and mandibular molar intrusion were observed.

One study [40] included distal tipping of the canines in the maxilla and mandible with direct TADs. The results presented tipping of $9.51^{\circ}$ in the study group and $6.51^{\circ}$ in the control group in the maxilla $(P=0.106)$; in the mandible, the results showed tipping of $7.88^{\circ}$ in the study group and $4.34^{\circ}$ in the control group $(P=0.057)$.

\section{Discussion}

\section{Summary of the evidence}

Since all meta-analyses included comparable results regardless of the study type (RCT or CCT), the GRADE

Table 3 Assessment of bias using the Risk of Bias In Non-randomised Studies (ROBINS-I) tool

\begin{tabular}{|c|c|c|c|c|c|c|c|c|}
\hline $\begin{array}{l}\text { Authors (years } \\
\text { of publication) }\end{array}$ & $\begin{array}{l}\text { Bias due to } \\
\text { confounding }\end{array}$ & $\begin{array}{l}\text { Bias in selection } \\
\text { of participants } \\
\text { into the study }\end{array}$ & $\begin{array}{l}\text { Bias in } \\
\text { classification of } \\
\text { interventions }\end{array}$ & $\begin{array}{l}\text { Bias due to } \\
\text { deviations from } \\
\text { intended } \\
\text { interventions }\end{array}$ & $\begin{array}{l}\text { Bias due } \\
\text { to } \\
\text { missing } \\
\text { data }\end{array}$ & $\begin{array}{l}\text { Bias in } \\
\text { measurement } \\
\text { of outcomes }\end{array}$ & $\begin{array}{l}\text { Bias in } \\
\text { selection of } \\
\text { the reported } \\
\text { result }\end{array}$ & $\begin{array}{l}\text { Overall } \\
\text { bias }\end{array}$ \\
\hline $\begin{array}{l}\text { Thiruvenkatachari } \\
\text { et al., } 2006 \text { [38] }\end{array}$ & Low & Moderate & Low & Low & Low & Serious & Low & Serious \\
\hline $\begin{array}{l}\text { Hedayati et al., } \\
2007 \text { [37] }\end{array}$ & Low & Moderate & Low & Low & Low & No information & Low & Moderate \\
\hline $\begin{array}{l}\text { Thiruvenkatachari } \\
\text { et al., } 2008 \text { [39] }\end{array}$ & Low & Moderate & Low & Low & Low & Serious & Low & Serious \\
\hline $\begin{array}{l}\text { Borsos et al.,2012 } \\
\text { [15] }\end{array}$ & Low & Low & Low & Low & Low & Low & Low & Low \\
\hline $\begin{array}{l}\text { Chaudhary et al., } \\
2014 \text { [40] }\end{array}$ & Low & Low & Low & Low & Low & Serious & Low & Serious \\
\hline
\end{tabular}




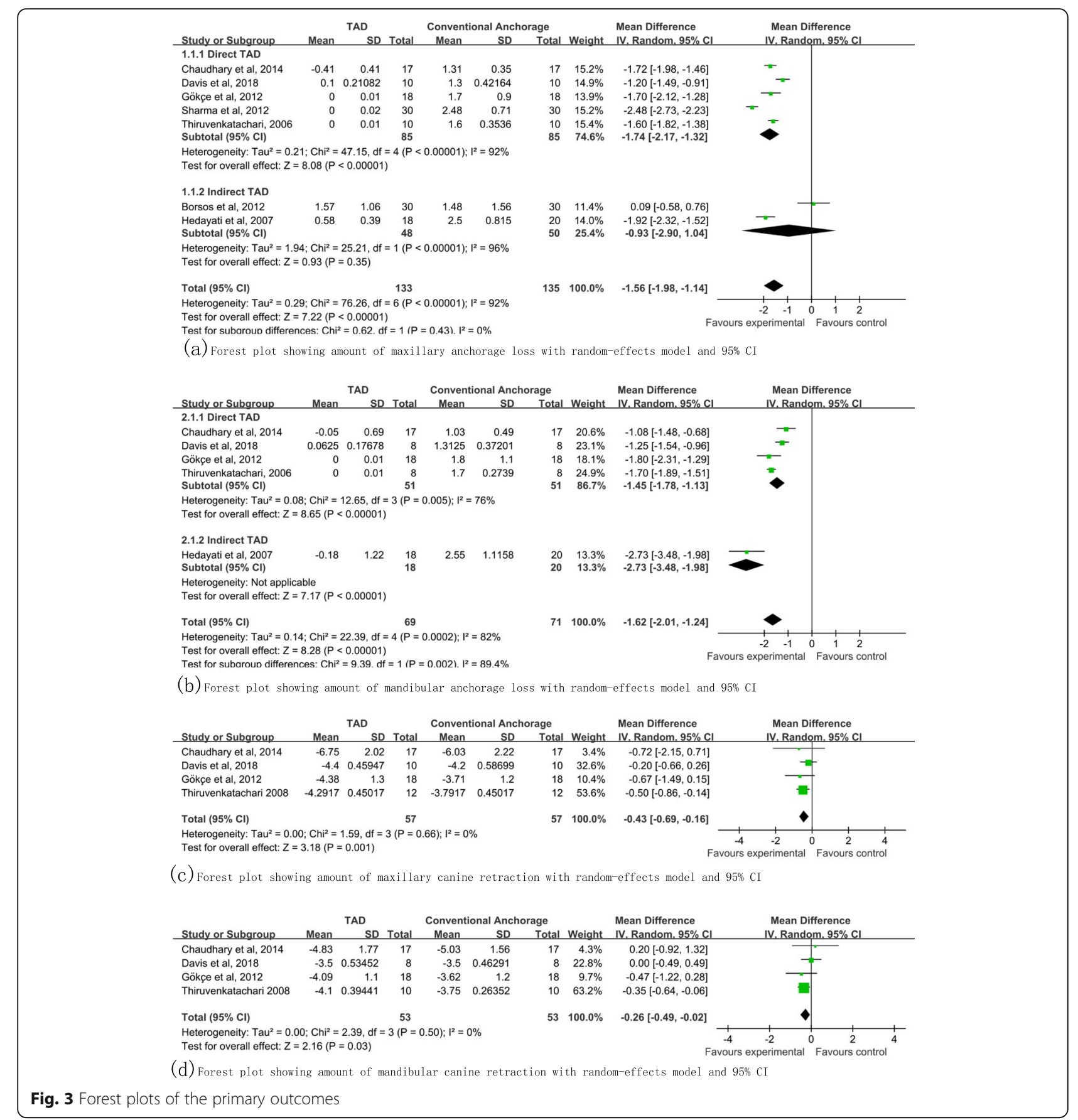

assessment was processed according to study type for each result. The GRADE recommendations represented very low quality for all of the results. The evidence for all comparisons was determined as being very low quality owing to risk of bias, inconsistency and imprecision. Detailed information is given in Table 4.

All eight studies [14, 15, 32, 33, 37-40] included patients requiring maximum anchorage for space closure. Although there were three articles [14, 38, 39] using different implant strategies, this did not seem to affect the final results, since the mandibular data without implants were not included in the study.

\section{Summary of the results}

Anchorage reinforcement during the space closure stage is a major issue in orthodontic treatment [4]. Conventionally, anchorage is provided by the molar units, a transpalatal arch (TPA), a Nance button or headgear; however, undesirable significant anchorage loss can still occur [42]. TADs are regarded as an ideal alternative 
Table 4 Summary of findings table according to the GRADE approach

\begin{tabular}{|c|c|c|c|}
\hline Outcomes (study design) & No of Participants (studies) & Quality of evidence (GRADE) & $\begin{array}{l}\text { Anticipated absolute } \\
\text { effects }(95 \% \mathrm{Cl})\end{array}$ \\
\hline Maxillary anchorage loss (randomised trials) & $\begin{array}{l}116 \\
\text { (3 studies) }\end{array}$ & $\begin{array}{l}\oplus \ominus \ominus \ominus \\
\text { VERY LOW } \\
\text { due to risk of bias, inconsistency, } \\
\text { imprecision }\end{array}$ & $\begin{array}{l}\text { 1.8 lower } \\
\text { ( } 2.63 \text { to } 0.96 \text { lower) }\end{array}$ \\
\hline Mandibular anchorage loss (randomised trials) & $\begin{array}{l}52 \\
\text { ( } 2 \text { studies) }\end{array}$ & $\begin{array}{l}\oplus \ominus \ominus \ominus \\
\text { VERY LOW } \\
\text { due to risk of bias, inconsistency, } \\
\text { imprecision }\end{array}$ & $\begin{array}{l}1.48 \text { lower } \\
\text { (2.02 to } 0.95 \text { lower) }\end{array}$ \\
\hline Maxillary anchorage loss (observational studies) & $\begin{array}{l}152 \\
\text { (4 studies) }\end{array}$ & $\begin{array}{l}\oplus \ominus \ominus \ominus \\
\text { VERY LOW } \\
\text { due to risk of bias, inconsistency, } \\
\text { imprecision }\end{array}$ & $\begin{array}{l}\text { 1.39 lower } \\
\text { (1.89 to } 0.88 \text { lower) }\end{array}$ \\
\hline $\begin{array}{l}\text { Mandibular anchorage loss (observational } \\
\text { studies) }\end{array}$ & $\begin{array}{l}88 \\
\text { ( } 3 \text { studies) }\end{array}$ & $\begin{array}{l}\oplus \ominus \ominus \ominus \\
\text { VERY LOW } \\
\text { due to risk of bias, inconsistency, } \\
\text { imprecision }\end{array}$ & $\begin{array}{l}\mathbf{1 . 7 6} \text { lower } \\
\text { (2.41 to } 1.1 \text { lower) }\end{array}$ \\
\hline Maxillary canine retraction (randomised trials) & $\begin{array}{l}56 \\
\text { ( } 2 \text { studies) }\end{array}$ & $\begin{array}{l}\oplus \ominus \ominus \ominus \\
\text { VERY LOW } \\
\text { due to risk of bias, imprecision }\end{array}$ & $\begin{array}{l}\mathbf{0 . 3 1} \text { lower } \\
\text { ( } 0.72 \text { lower to } 0.09 \text { higher) }\end{array}$ \\
\hline Mandibular canine retraction (randomised trials) & $\begin{array}{l}52 \\
\text { ( } 2 \text { studies) }\end{array}$ & $\begin{array}{l}\oplus \ominus \ominus \ominus \\
\text { VERY LOW } \\
\text { due to risk of bias, inconsistency, } \\
\text { imprecision }\end{array}$ & $\begin{array}{l}\mathbf{0 . 1 4} \text { lower } \\
\text { ( } 0.28 \text { lower to } 0.57 \text { higher })\end{array}$ \\
\hline Maxillary canine retraction (observational studies) & $\begin{array}{l}58 \\
\text { ( } 2 \text { studies) }\end{array}$ & $\begin{array}{l}\oplus \ominus \ominus \ominus \\
\text { VERY LOW } \\
\text { due to risk of bias, imprecision }\end{array}$ & $\begin{array}{l}\mathbf{0 . 5 1} \text { lower } \\
\text { ( } 0.86 \text { to } 0.16 \text { lower) }\end{array}$ \\
\hline $\begin{array}{l}\text { Mandibular canine retraction (observational } \\
\text { studies) }\end{array}$ & $\begin{array}{l}54 \\
\text { ( } 2 \text { studies) }\end{array}$ & $\begin{array}{l}\oplus \ominus \ominus \ominus \\
\text { VERY LOW } \\
\text { due to risk of bias, inconsistency, } \\
\text { imprecision }\end{array}$ & $\begin{array}{l}\mathbf{0 . 3 1} \text { lower } \\
(0.6 \text { to } 0.03 \text { lower })\end{array}$ \\
\hline
\end{tabular}

method for reinforcing anchorage in en masse retraction, but whether they produce the same effect in canine retraction is inconclusive. The purpose of this systematic review was to evaluate the effectiveness of TADs during canine retraction.

The results of the meta-analysis show that minimizing mesial molar movement is most effectively achieved with TADs. Specifically, overall anchorage preservation of $1.61 \mathrm{~mm}$ and $1.62 \mathrm{~mm}$ was found in the maxilla and mandible, respectively, which is meaningful compared with that achieved by conventional anchorage methods. However, the results of the subgroup analysis are different. TADs between the second premolar and the first molar on the buccal side cause the molar not to be subjected to any force that will lead to movement. However, indirect TADs in the maxilla had no significant effect on anchorage preservation. The reason may be that the forces in different directions cannot be completely offset, which results in the anchoring teeth being subjected to force, despite indirect reinforcement of the teeth by a steel wire or TPA. The use of indirect implant anchorage is controversial. Ozkan et al. [43] noted that the form of implant anchorage did not affect the results; however, Jang et al. [44] indicated that an indirectly anchored tooth will move mesially with indirect implant anchorage. Additionally, deformation of the TPA $[45,46]$ brought about by orthodontic force might be another reason for mesial molar movement in the indirect implant group. There is evidence suggesting that some extent of molar retraction may be achieved with TADs, as reported by Chaudhary et al., 2014 [40], and Hedayati et al., 2007 [37]. However, the purpose of these two studies was not to distalize molars, but only to preserve anchorage. The tight fastening between the molar and implant for indirect implants, which are located more distally [37], and friction between the buccal tube and the archwir e[13] for direct implants may be reasons for molar retraction. Therefore, on the basis of very lowquality evidence, direct implant anchorage reinforcement can be considered clinically significant. However, considering the few published articles, the role of indirect implant anchorage with respect to anchorage preservation during canine retraction remains inconclusive.

In our review, two included studies $[15,37]$ applied palatal implants to reinforce posterior teeth with or without a TPA for indirect implant anchorage in the maxilla. A TPA with a palate implant may cause a marked foreign body sensation and patient discomfort 
[46]. Substantial clinical heterogeneity existed in the meta-analysis because the included studies varied significantly in the use of osseointegrated and nonosseointegrated implants, study type, bracket slot sizes, archwires and measurement methods.

Canine retraction is the first step of the two-step technique for space closure [20]. Clinically, the extent of canine movement is of great importance for subsequent incisor retraction, especially for patients with dentoalveolar protrusion. Some studies $[14,33,40]$ have measured the rate of canine retraction, but considering that different magnitudes of force are used in canine retraction, only the extent of retraction was included in the statistical synthesis. In particular, $0.41 \mathrm{~mm}$ and $0.25 \mathrm{~mm}$ of canine retraction in the maxilla and mandible, respectively, was consistent with increased anchorage preservation, and increased canine retraction could be achieved with direct implant anchorage. No studies of indirect anchorage were included in this meta-analysis. Therefore, no conclusions regarding indirect implant anchorage can be drawn. Generally, on the basis of very low-quality evidence, direct implant anchorage could facilitate greater canine retraction.

Anchorage loss may also be accompanied by tipping of the molars, but with direct anchorage using TADs, the retraction force acts directly on the canines and away from the molars during retraction. The molars will not be subjected to any force that may lead to excessive molar tipping.

Vertical molar displacement indicates movement of the molar perpendicular to the occlusal plane, usually with intrusion or extrusion. The mesial tipping and extrusion of a molar may lead to an undesirable change in the vertical dimension of the face, which is crucial for the orthodontic treatment of high-angle patients [47]. Tightened ligation between the implant and tooth may exert force to intrude the molar [37]. The implant does have the ability to intrude molars in open-bite cases with elastomeric traction [48]. Implants with a relatively gingival position are more closely or elastically connected, and indirect implants may have the effect of molar intrusion. An implant between the second premolar and the first molar can act as a direct implant, and a ligature wire engaged between the second premolar and the implant can also act as an indirect implant, as reported by Sharma et al. [32].

Bodily canine movement is important for achieving a class I canine relationship, and tipping is undesirable. Herman et al. [3] indicated that canine tipping is related to the method used to ligate the canines to the archwire, with the most bodily canine retraction, perhaps with slight tipping, being achieved using direct implants. However, the bracket slot, archwire size and residual gap may affect canine tipping the most. The better matched the size, the lesser is the tilt [49]. In terms of biomechanics, the occurrence of bodily movement or tipping depends on the relationship between the center of resistance and the direction of the force, i.e., whether the direction of the forces passes through the resistance center. The results show greater canine tipping in the implant group. However, adjustment of the height relationship between the crimpable hook and implant may allow the desired bodily tooth movement to be achieved [50]. Implant anchorage may allow the direction of the force to vary to adjust the extent of tipping during the process.

\section{Limitations}

The number of studies that could be included was relatively small, and the overall quality of the RCTs and CCTs was very low. In particular, there are few studies regarding indirect implant anchorage, which makes drawing a definitive conclusion impossible. The heterogeneity in the meta-analysis of anchorage preservation was relatively high. Due to the small number of articles, publication bias could not be assessed by funnel plot.

\section{Conclusions}

1. During canine retraction, direct TADs can result in better anchorage preservation and canine retraction than conventional anchorage methods.

2. Very low-quality evidence prevents a credible conclusion from being drawn. Further high-quality studies comparing conventional anchorage and TADs during canine retraction are needed.

\section{Supplementary information}

Supplementary information accompanies this paper at https://doi.org/10. 1186/s12903-020-01271-8.

Additional file 1. Searching strategy

Additional file 2. Articles Excluded After Full-Text Evaluation Based on Eligibility Criteria

\section{Abbreviations \\ RCTs: Randomized Controlled Trials; CCTs: Controlled Clinical Trials; ROBINS- I: Risk of Bias in Nonrandomized Studies - of Interventions; GRADE: Grades of Recommendation, Assessment, Development and Evaluation; \\ TPA: Transpalatal Arch; TADs: Temporary Anchorage Devices; PRIS MA: Preferred Reporting Items for Systematic Reviews and Meta-Analyses; $\mathrm{Cl}$ : Confidence Interval; SD: Standard Deviation}

Acknowledgements

Not applicable.

Authors' contributions

THN and XCM have made contributions to study design, acquisition of data and draft the manuscript. YHM and LM have been involved in analysis and interpretation of data. RAS have been involved in revising manuscript critically and given final approval of the version to be published. All authors have read and approved the manuscript. 


\section{Funding}

This work was supported by etiology and prevention research of oral diseases of Chongqing Medical University (CXTDG201602006) for data collection, analysis, and interpretation and in writing the manuscript.

\section{Availability of data and materials}

All data generated or analysed during this study are included in this published article and its supplementary information files.

\section{Ethics approval and consent to participate}

Not applicable.

\section{Consent for publication}

Not applicable.

\section{Competing interests}

The authors declare that they have no competing interests.

\section{Author details}

${ }^{1}$ College of Stomatology, Chongqing Medical University, No.426 Songshibeilu Road, Yubei District, Chongqing, China. ${ }^{2}$ Chongqing Key Laboratory of Oral Diseases and Biomedical Sciences, Chongqing, China. ${ }^{3}$ Chongqing Municipal Key Laboratory of Oral Biomedical Engineering of Higher Education, Chongqing, China.

\section{Received: 4 December 2019 Accepted: 1 October 2020}

\section{Published online: 10 October 2020}

\section{References}

1. Ingram AH. Premolar enucleation. The Angle orthodontist. 1976;46(3):21931.

2. Burrow SJ. To extract or not to extract: a diagnostic decision, not a marketing decision. American journal of orthodontics and dentofacial orthopedics : official publication of the American Association of Orthodontists, its constituent societies, and the American Board of Orthodontics. 2008:133(3):341-2.

3. Herman RJ, Currier GF, Miyake A. Mini-implant anchorage for maxillary canine retraction: a pilot study. Am J Orthodontics Dentofacial Orthopedics. 2006;130(2):228-35.

4. Melsen B, Bosch C. Different approaches to anchorage: a survey and an evaluation. The Angle orthodontist. 1997;67(1):23-30.

5. Rizk MZ, Mohammed $H$, Ismael $O$, Bearn DR. Effectiveness of en masse versus two-step retraction: a systematic review and meta-analysis. Prog Orthod. 2018;18(1):41.

6. Zablocki HL, McNamara JA Jr, Franchi L, Baccetti T. Effect of the transpalatal arch during extraction treatment. Am J Orthodontics Dentofacial Orthop. 2008;133(6):852-60.

7. Ning M, Weiran L. Comparison of treatment outcomes in patients with maxillary dentoalveolar protrusion by applying different anchorage methods: a three-dimensional model study. Hua xi kou qiang yi xue za zhi $=$ Huaxi kouqiang yixue zazhi $=$ West China journal of stomatology. 2015. 33(1):63-6.

8. Cole WA. Accuracy of patient reporting as an indication of headgear compliance. American journal of orthodontics and dentofacial orthopedics. 2002;121(4):419-23.

9. Diar-Bakirly S, Feres MF, Saltaji H, Flores-Mir C, El-Bialy T. Effectiveness of the transpalatal arch in controlling orthodontic anchorage in maxillary premolar extraction cases: a systematic review and meta-analysis. The Angle orthodontist. 2017;87(1):147-58.

10. Stivaros N, Lowe C, Dandy N, Doherty B, Mandall NA. A randomized clinical trial to compare the Goshgarian and Nance palatal arch. Eur J Orthod. 2010; 32(2):171-6

11. Benson PE, Tinsley D, O'Dwyer JJ, Majumdar A, Doyle P, Sandler PJ. Midpalatal implants vs headgear for orthodontic anchorage - a randomized clinical trial: Cephalometric results. Am J Orthod Dentofac Orthop. 2007: 132(5):606-15

12. Wahl N. Orthodontics in 3 millennia. Chapter 15: skeletal anchorage. Am J Orthod Dentofac Orthop. 2008;134(5):707-10.

13. Antoszewska-Smith J, Sarul M, Lyczek J, Konopka T, Kawala B. Effectiveness of orthodontic miniscrew implants in anchorage reinforcement during en- masse retraction: a systematic review and meta-analysis. Am J Orthodontics Dentofacial Orthopedics. 2017:151(3):440-55.

14. Davis D, Krishnaraj R, Duraisamy S, Ravi K, Dilip S, Charles A, Sushil NC. Comparison of rate of canine retraction and Anchorage potential between mini-implant and conventional molar Anchorage: an in vivo study. Contemporary clinical dentistry. 2018:9(3):337-42.

15. Borsos G, Voko Z, Gredes T, Kunert-Keil C, Vegh A. Tooth movement using palatal implant supported anchorage compared to conventional dental anchorage. Annals of anatomy = Anatomischer Anzeiger. 2012;194(6):556-60.

16. Abdulnabi $Y$, Albogha MH, Abuhamed $\mathrm{H}$, Kaddah A. Non-surgical treatment of anterior open bite using miniscrew implants with posterior bite plate. Orthodontic Waves. 2017;76(1):40-5.

17. Feldmann I, Bazargani F. Pain and discomfort during the first week of rapid maxillary expansion (RME) using two different RME appliances: a randomized controlled trial. The Angle orthodontist. 2017:87(3):391-6.

18. Heo W, Nahm DS, Baek SH. En masse retraction and two-step retraction of maxillary anterior teeth in adult class I women. A comparison of anchorage loss. The Angle orthodontist. 2007;77(6):973-8.

19. Pervin S, Rolland S, Taylor G. En masse versus two-step retraction of the anterior segment. Evidence-based dentistry. 2018;19(4):111-2.

20. Schneider PP, Gandini Junior LG, Monini ADC, Pinto ADS, Kim KB. Comparison of anterior retraction and anchorage control between en masse retraction and two-step retraction: a randomized prospective clinical trial. The Angle orthodontist. 2019;89(2):190-9.

21. Schneider PP, Kim KB, Monini ADC, Santos-Pinto AD, Gandini Junior LG. Which one closes extraction spaces faster: en masse retraction or two-step retraction? A randomized prospective clinical trial. The Angle orthodontist. 2019

22. Khlef HN, Hajeer MY, Ajaj MA, Heshmeh O. Evaluation of treatment outcomes of en masse retraction with temporary skeletal Anchorage devices in comparison with two-step retraction with conventional Anchorage in patients with Dentoalveolar protrusion: a systematic review and meta-analysis. Contemporary clinical dentistry. 2018;9(4):513-23.

23. Upadhyay M, Yadav S, Nagaraj K, Patil S. Treatment effects of mini-implants for en-masse retraction of anterior teeth in bialveolar dental protrusion patients: a randomized controlled trial. Am J Orthodontics Dentofacial Orthop. 2008;134(1):18-29 e11.

24. Antoszewska-Smith J, Sarul M, Łyczek J, Konopka T, Kawala B. Effectiveness of orthodontic miniscrew implants in anchorage reinforcement during enmasse retraction: a systematic review and meta-analysis. Am J Orthod Dentofac Orthop. 2017:151(3):440-55.

25. Xu TM, Zhang X, Oh HS, Boyd RL, Korn EL, Baumrind S. Randomized clinical trial comparing control of maxillary anchorage with 2 retraction techniques, American journal of orthodontics and dentofacial orthopedics. 2010;138(5): 544.e541-549 discussion 544-545.

26. Nanda R, Kuhlberg A, Uribe F. CHAPTER 10 - Biomechanic Basis of Extraction Space Closure. In: Saint Louis NR, editor. Biomechanics and Esthetic Strategies in Clinical Orthodontics: W.B. Saunders; 2005. p. 194-210.

27. Rajesh M, Kishore M, Shetty KS. Comparison of anchorage loss following initial leveling and aligning using ROTH and MBT prescription - a clinical prospective study. J Int Oral Health. 2014;6(2):16-21.

28. McLaughlin RP, Bennett JC. Anchorage control during leveling and aligning with a preadjusted appliance system. J Clinical Orthodontics. 1991;25(11):687-96.

29. Talapaneni AK, Supraja G, Prasad M, Kommi PB. Comparison of sagittal and vertical dental changes during first phase of orthodontic treatment with MBT vs ROTH prescription. Indian J Dental Res. 2012;23(2):182-6.

30. Celenza F, Hochman MN. Absolute anchorage in orthodontics: direct and indirect implant-assisted modalities. J Clin Orthodontics. 2000;34(7):397-402.

31. Kim KA, Chen Y, Kwon SY, Seo KW, Park KH, Kim SH. Versatile clinical application of the spike screw: direct Anchorage versus indirect Anchorage. The Journal of craniofacial surgery. 2015;26(7):e592-5.

32. Sharma M, Sharma $V$, Khanna B. Mini-screw implant or transpalatal archmediated anchorage reinforcement during canine retraction: a randomized clinical trial. J Orthod. 2012;39(2):102-10.

33. Gökçe SM, Görgülü S, Gökçe HS, Yýldýrým E, Saðdýç D. Comparison of conventional molar tooth anchorage and micro-implant anchorage regarding canine retraction in treatments with extraction. Gulhane Med J. 2012:No.3:205-11.

34. Moher D, Liberati A, Tetzlaff J, Altman DG. Preferred reporting items for systematic reviews and meta-analyses: the PRISMA statement. BMJ (Clinical research ed). 2009;339:b2535. 
35. Higgins JP, Altman DG, Gotzsche PC, Juni P, Moher D, Oxman AD, Savovic J, Schulz KF, Weeks L, Sterne JA. The Cochrane Collaboration's tool for assessing risk of bias in randomised trials. BMJ (Clinical research ed). 2011; 343:d5928.

36. Sterne JA, Hernan MA, Reeves BC, Savovic J, Berkman ND, Viswanathan M, Henry D, Altman DG, Ansari MT, Boutron I, et al. ROBINS-I: a tool for assessing risk of bias in non-randomised studies of interventions. BMJ (Clinical research ed). 2016;355:14919.

37. Hedayati Z, Hashemi SM, Zamiri B, Fattahi HR. Anchorage value of surgical titanium screws in orthodontic tooth movement. Int J Oral Maxillofac Surg. 2007;36(7):588-92.

38. Thiruvenkatachari B, Pavithranand A, Rajasigamani K, Kyung HM. Comparison and measurement of the amount of anchorage loss of the molars with and without the use of implant anchorage during canine retraction. Am J Orthod Dentofacial Orthop. 2006;129(4):551-4.

39. Thiruvenkatachari B, Ammayappan P, Kandaswamy R. Comparison of rate of canine retraction with conventional molar anchorage and titanium implant anchorage. Am J Orthod Dentofacial Orthop. 2008;134(1):30-5.

40. Chaudhary G, Sidhu MS, Grover S, Chaudhry A. Cone-beam computerized tomography evaluation of canine retraction using micro implant and conventional anchorage. Journal of Pierre Fauchard Academy (India Section). 2014;28(2):35-42.

41. Borsos G, Vokó Z, Gredes T, Kunert-Keil C, Vegh A. Tooth movement using palatal implant supported anchorage compared to conventional dental anchorage. Ann Anat. 2012;194(6):556-60.

42. Geron S, Shpack N, Kandos S, Davidovitch M, Vardimon AD. Anchorage loss--a multifactorial response. The Angle orthodontist. 2003;73(6):730-7.

43. Ozkan S, Bayram M. Comparison of direct and indirect skeletal anchorage systems combined with 2 canine retraction techniques. Am J Orthod Dentofacial Orthop. 2016;150(5):763-70.

44. Jang W, Choi YJ, Hwang S, Chung CJ, Kim KH. Anchorage loss assessment of the indirect anchor tooth during adjunctive orthodontic treatment. Am J Orthod Dentofacial Orthop. 2019;155(3):347-54.

45. Wehrbein $\mathrm{H}$, Feifel $\mathrm{H}$, Diedrich P. Palatal implant anchorage reinforcement of posterior teeth: a prospective study. Am J Orthod Dentofac Orthop. 1999; 116(6):678-86.

46. Crismani AG, Celar AG, Burstone CJ, Bernhart TG, Bantleon HP, Mittlboeck M. Sagittal and vertical load-deflection and permanent deformation of transpalatal arches connected with palatal implants: an in-vitro study. Am J Orthod Dentofacial Orthop. 2007;131(6):742-52.

47. Kouvelis G, Dritsas K, Doulis I, Kloukos D, Gkantidis N. Effect of orthodontic treatment with 4 premolar extractions compared with nonextraction treatment on the vertical dimension of the face: a systematic review. Am J Orthod Dentofacial Orthop. 2018;154(2):175-87.

48. Hart TR, Cousley RR, Fishman LS, Tallents RH. Dentoskeletal changes following mini-implant molar intrusion in anterior open bite patients. The Angle orthodontist. 2015;85(6):941-8.

49. Huffman DJ, Way DC. A clinical evaluation of tooth movement along arch wires of two different sizes. Am J Orthod. 1983;83(6):453-9.

50. Gu YJ, Wu YP, Gao MQ, Yao N, Chen WJ. Finite element analysis of mechanical characteristics during retracting mandibular incisors through sliding mechanics. Shanghai kou qiang yi xue = Shanghai J Stomatology. 2008;17(5):520-4.

\section{Publisher's Note}

Springer Nature remains neutral with regard to jurisdictional claims in published maps and institutional affiliations.

Ready to submit your research? Choose BMC and benefit from:
- fast, convenient online submission
- thorough peer review by experienced researchers in your field
- rapid publication on acceptance
- support for research data, including large and complex data types
- gold Open Access which fosters wider collaboration and increased citations
- maximum visibility for your research: over 100M website views per year
At BMC, research is always in progress.
Learn more biomedcentral.com/submissions

